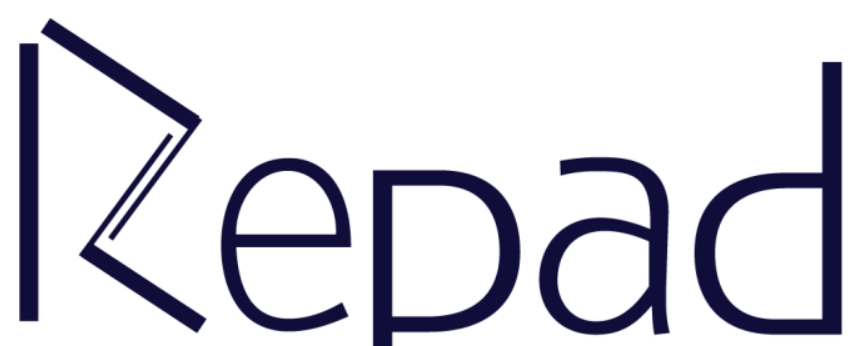

v. 4, n. 2, Maio-Agosto/2020

Revista Estudos e

Pesquisas em Administração 


\title{
COMPETITIVIDADE LOGÍSTICA AEROPORTUÁRIA NO BRASIL
}

\author{
William Marques \\ william_marques@ hotmail.com \\ http://orcid.org/0000-0002-5715-2342 \\ Universidade de Brasilia \\ Brasilia-Dis trito Federal, Brasil \\ Augusto Cesar de Mendonça Brasil \\ http://orcid.org/0000-0002-0009-9798 \\ Universidade de Brasília \\ Brasilia-Dis trito Federal, Brasil
}

\section{Resumo}

A desregulação da infraestrutura aeroportuária no Brasil é um marco no setor, induzindo o mercado a uma competição mais acirrada entre os aeroportos e maiores investimentos nas infraestruturas aeroportuárias. Este estudo teve por objetivo identificar as variáveis determinantes para o desempenho logístico dos terminais de carga das administradoras aeroportuárias, aplicáveis ao caso brasileiro, e mensurar a competitividade, pelo critério da eficiência, dos 12 principais terminais de carga, que correspondem a 97,39\% da movimentação no Brasil. A abordagem contemplou cinco dimensões: infraestrutura, operação, demanda, receita, localização e serviço, desmembradas em 22 variáveis. Adotando a análise de componentes principais, foram identificadas as variáveis que retiveram maiores informações sobre os aeroportos e obtidos os pesos dessas variáveis a partir da normalização dos 3 componentes principais que explicam 85,55\% da variância total dos dados. Os resultados apontaram que as variáveis de maior relevância são, na ordem de importância, fluxo total carga origem-destino doméstico, movimento anual pouso-decolagem, quantidade de posições no pátio de aeronaves e quantidade de ligações (conexões) áreas domésticas. $\mathrm{O}$ aeroporto mais eficiente, considerando a produtividade agregada medida pela razão entre inputs e outputs, é Viracopos, seguido por Manaus, Guarulhos, Curitiba, Galeão, Confins, Porto Alegre, Goiânia, Recife, Fortaleza, Salvador e Brasilia.

Palavras-chave: Aeroport; Carga Aérea; Competitividade; Infraestrutura.

\section{AIRPORT LOGISTIC COMPETITIVENESS IN BRAZIL}

\begin{abstract}
The deregulation of airport infrastructure in Brazil is a milestone in the sector, leading the market to more fierce competition between airports and greater investments in airport infrastructure. This study aims to identify the determining variables for the logistical performance of the airport terminals' cargo terminals, applicable to the Brazilian case, and measure the competitiveness, by the efficiency criterion, of the 12 main cargo terminals, which correspond to $97.39 \%$ movement in Brazil. The approach included five dimensions: infrastructure, operation, demand, revenue, location and service, broken down into 22 variables. Adopting the principal component analysis, the variables that retain more information about the airports were identified and the weights
\end{abstract}


of the variables were obtained from the normalization of the 3 main components that explain $85.55 \%$ of the total data information. The results show that the most relevant variables are, in order of importance, total domestic origin-destination cargo flow, annual landing-takeoff movement, number of positions in the aircraft yard and number of connections (connections) to domestic areas. The most efficient airport, considering the aggregate productivity measured by the ratio between inputs and outputs, is Viracopos, followed by Manaus, Guarulhos, Curitiba, Galeão, Confins, Porto Alegre, Goiânia, Recife, Fortaleza, Salvador and Brasilia.

Keywords: Airport; Air Cargo; Competitiveness; Infrastructure.

Submetido: 09/03/2020

Aceito: 05/05/2020

Publicado: 31/05/2020

\section{Introdução}

Os estudos em competitividade aeroportuária centraram-se principalmente no mercado de passageiros e transportadores aéreos. No mercado de carga aérea, o potencial de atratividade de carga de um aeroporto está relacionado não somente a infraestrutura disponível, mas a fatores de localização (concentração das atividades industriais e comerciais, à cadeia de suprimentos e ao nível de riqueza expresso pelo PIB), fatores de demanda (volume transportado origem-destino), de operação (ligações aéreas e fluxo de aeronaves) e financeiros (receita, custos e resultados) e infraestrutura aeroportuária.

O Governo brasileiro concentrou seus estudos em três importantes mercados de concorrência entre os aeroportos: (i) concorrência nas áreas de captação; (ii) competição para conectar passageiros; e (iii) competição por carga. A análise, portanto, focou-se na concorrência relacionada com a ligação de passageiros e carga, considerando que havia concorrência potencial entre os aeroportos para ligações de passageiros e, em alguns casos, para carga. Os estudos demonstraram concorrência potencial entre os aeroportos para se tornarem centros internacionais ou nacionais, e possivelmente se transformar em hubs de carga, enfatizando a importância da restrição da propriedade cruzada para permitir a implementação bem-sucedida da concorrência (NETO et al., 2016).

Há poucos estudos que investigaram a competitividade de mercados de carga entre aeroportos, os quais se destacam Larrodé et al. (2018); Wong, Chung e Hsu (2016); Chao e Yu, (2013); Lee (2007); Senguttuvan (2006); Gardiner, Ison e Humphreys (2005); McKinnon, (2011); e Zhang (2003). Os autores avaliaram a competitividade logística aeroportuária a partir de variáveis como frequência de voo, distribuição de rotas (origem-destino), distribuição e quantidade de transportadoras (nacionais e estrangeiras) e agentes de carga, restrições de operação, capacidade de transporte (aeronaves de passageiros e/ou cargueiros), demanda (volume de carga), instalações aeroportuárias, taxas aeroportuárias, tempos de desembaraço de carga, automação de armazéns, fatores econômicos como nível de desenvolvimento regional, fatores financeiros (receitas, produtividade e custos da atividade de carga), fatores de distribuição como intermodalidade, malha viária e tempos de entrega de mercadoria, entre outros. 
A partir do cenário do mercado logístico aéreo nacional, questiona-se: O que faz os aeroportos líderes serem mais competitivos e eficientes no mercado de carga aérea? Qual a semelhança entre esses aeroportos? Quais são as variáveis necessárias para se avaliar o desempenho aeroportuário relativo à carga aérea e como mensurar a eficiência dos aeroportos?

Analisar o desempenho logístico relativo à carga aérea é complexo, pois somente modelos de análise multivariada podem responder as perguntas supracitadas, pois o mercado é influenciado não somente por fatores relacionados diretamente à carga aérea, mas por uma série de variáveis, tanto exógenas quanto endógenas, relacionadas à infraestrutura aeroportuária e às características regionais em que os aeroportos estão inseridos.

Este estudo teve por objetivo identificar as variáveis determinantes de competitividade dos terminais de carga aeroportuários e mensurar a competitividade, pelo critério da eficiência, dos 12 principais terminais de carga: Guarulhos, Viracopos, Manaus, Galeão, Porto Alegre, Curitiba, Recife, Confins, Salvador, Goiânia, Fortaleza e Brasilia.

Para o alcance dos objetivos foram selecionadas 22 variáveis passíveis de quantificação, contemplando as cinco dimensões: infraestrutura, operação, demanda, receita, localização e serviço. São elas: conexões empresariais, PIB da rede de influência, PIB per capita da rede, posições do pátio aeronaves, área do pátio aeronaves, área terminal de carga importação, exportação e doméstico, comprimento linear total pistas, volume em toneladas anual de carga importação, exportação e doméstica, fluxo origem e destino doméstico total, movimento anual pouso decolagem, movimento anual de cargueiros, companhias aéreas operando, ligações aéreas domésticas (conexões), faturamento, resultado (faturamento-custos), tempo desembaraço aduaneiro, processamento carga (ton./área) e produtividade não agregada (resultado/peso).

Com a transferência da administração dos aeroportos a partir de 2011, os relatórios disponibilizados pela INFRAERO não consideram a movimentação nos terminais de carga (TECA) concedidos após a transferência de administração. A SAC e Ministério da Infraestrutura não disponibilizam dados referentes ao setor de carga aérea e a ANAC apenas informações limitadas dos aeroportos brasileiros, tais como movimentação total das companhias aéreas englobando todos os aeroportos e movimentação total de carga por aeroporto sem, no entanto, discriminar o movimentado nos terminais próprios das Concessionárias ou INFRAERO. De tal forma, o recorte temporal possível é do ano de 2010 para comparação entre as variáveis.

\section{Panorama do Setor de Carga Aeroportuário Brasileiro}

Apesar da mudança no mercado ocasionada pelo processo de desregulação da aviação civil no Brasil, que reduziu a área de cobertura do transporte doméstico, houve por outro lado um aumento na quantidade de pessoas transportadas devido à redução tarifária significativa, estabilidade econômica do país com a implementação do Plano Real e a concentração da malha, proporcionando o crescimento econômico do setor e, por conseguinte, um aumento na movimentação de cargas nos porões das aeronaves de passageiros.

No Brasil o fluxo de carga área é concentrado em aeroportos hubs, onde os três aeroportos de maior movimentação de carga - Guarulhos, Viracopos e Manaus corresponderam a $73,92 \%$ da movimentação total dos TECA dos 34 aeroportos brasileiros, incluindo importação, exportação e carga doméstica, de um montante de 
1.139.209 toneladas em 2010, com 33,15\%, 23,46\% e 17,32\% movimentados, respectivamente, seguidos em ordem decrescente pelos aeroportos internacionais Galeão (7,03\%), Porto Alegre (3,67\%), Curitiba (3,28\%), Recife (2,77\%), Confins $(1,71 \%)$, Salvador (1,64\%), Goiânia $(1,56 \%)$, Fortaleza $(1,08 \%)$ e Brasilia $(0,72 \%)$, totalizando $97,39 \%$ da movimentação. Os demais aeroportos obtiveram individualmente menos de $0,50 \%$ da movimentação em relação ao total (INFRAERO, 2010).

No que tange ao mercado doméstico, somente 14 aeroportos possuíam terminais de cargas (TECA) nacionais operantes, sendo os líderes em ordem decrescente em 2010: Manaus $(39,06 \%)$ do volume total, Guarulhos $(34,03 \%)$, Recife $(8,18 \%)$, Porto Alegre $(6,87 \%)$, Salvador (3,04\%), Fortaleza $(2,41 \%)$, Brasilia $(1,56 \%)$ e Curitiba $(1,56 \%)$, Porto Velho $(1,39 \%)$, Natal $(0,65 \%)$, Cuiabá $(0,58 \%)$, Campinas $(0,42 \%)$, João Pessoa $(0,18 \%)$ e Confins $(0,11 \%)$, de um montante de 313.027 toneladas. Aeroportos hubs como Viracopos e Confins movimentaram apenas 0,42\% e 0,11\%, respectivamente, enquanto Galeão e Goiânia não movimentaram cargas em terminais próprios (INFRAERO, 2010).

Ressalta-se que a movimentação apresentada diz respeito aos terminais de carga da Administradora Aeroportuária (INFRAERO), considerando o ano 2010, por ser o período pré-concessão e com dados secundários disponíveis ao público. A movimentação apresentada não engloba a movimentação de carga nos terminais das companhias aéreas, Empresa Brasileira de Correios e Telégrafos (ECT) e demais operadores logísticos, indisponíveis ao público.

Nota-se na Tabela 1, que a razão entre o fluxo doméstico origem-destino e o movimentado no TECA em relação à carga doméstica, que o administrador aeroportuário, INFRAERO na ocasião, detinha pouca parcela da movimentação geral, com exceção dos aeroportos de Manaus, Porto Alegre, Recife e Guarulhos, em que Manaus apresentou um montante superior ao fluxo de carga aérea, evidenciando que boa parte da carga neste aeroporto tem origem rodoviária.

Os aeroportos de maior destaque na carga internacional são Guarulhos e Viracopos, embora Viracopos tenha pouca movimentação de carga doméstica o que reflete seu pouco destaque no fluxo de aeronaves de passageiros, principal responsável pelo transporte de cargas domesticas. $\mathrm{O}$ aeroporto Galeão, terceiro em volume de cargas internacionais, apesar de ser o terceiro em movimento de passageiros no país, não explorava a atividade de armazenagem de cargas domésticas, assim como Goiânia, não apresentando moviventação.

Tabela 1. Movimentação nos Terminais de Carga Aeroportuários e fluxo total em toneladas

\begin{tabular}{|c|c|c|c|c|c|}
\hline Aeroporto & $\begin{array}{c}\text { Carga } \\
\text { Importação }\end{array}$ & $\begin{array}{c}\text { Carga } \\
\text { Exportação }\end{array}$ & $\begin{array}{c}\text { Carga } \\
\text { Doméstica }\end{array}$ & $\begin{array}{l}\text { Carga origem- } \\
\text { destino dom. } \\
\text { Geral }\end{array}$ & $\begin{array}{c}\text { Razão Carga } \\
\text { dom.TECA/Geral }\end{array}$ \\
\hline Guarulhos & $1.397,85$ & $129.670,13$ & 27,99 & $226.806,00$ & $46,97 \%$ \\
\hline Viracopos & 169.862 & $96.065,15$ & $1.316,14$ & $15.826,00$ & $8,32 \%$ \\
\hline Galeão & 45.796 & $34.273,41$ & & $50.972,00$ & $0,00 \%$ \\
\hline Confins & $12.367,58$ & $6.818,73$ & 344,21 & $24.570,00$ & $1,40 \%$ \\
\hline Brasilia & $2.994,31$ & 320,11 & $4.895,45$ & $88.219,00$ & $5,55 \%$ \\
\hline Manaus & 69.401 & $5.636,45$ & $122.269,81$ & $94.001,00$ & $130,07 \%$ \\
\hline & $.618,95$ & & $21.497,31$ & $27.138,00$ & $79,21 \%$ \\
\hline Curitiba & $21.241,92$ & $11.422,12$ & $4.693,75$ & $14.197,00$ & $33,06 \%$ \\
\hline Recife & $2.864,48$ & $3.128,70$ & $25.608,57$ & $49.806,00$ & $51,42 \%$ \\
\hline Salvador & $3.614,66$ & $5.527,74$ & $9.527,88$ & $47.687,00$ & $19,98 \%$ \\
\hline & $17.684,38$ & & & $9.955,00$ & $0,00 \%$ \\
\hline Fortaleza & $1.369,19$ & $3.403,37$ & $7.556,85$ & $42.129,00$ & $17,94 \%$ \\
\hline
\end{tabular}

Fonte. Infraero (2010) e Anac (2010) 
As principais rotas domésticas de carga aérea em 2010 foram as rotas ManausGuarulhos com 99.930 toneladas transportadas, seguida pela rota Fortaleza-Guarulhos com 16.652 toneladas, Recife-Guarulhos com 13.319 toneladas, Salvador-Guarulhos com 13.659 toneladas, Brasilia-Congonhas com 12.168 toneladas e Brasilia-Manaus com 9.729 toneladas, como ilustrado na Figura 1 à esquerda. Conforme projeção as principais rotas se mantém concentrando os maiores fluxos de carga doméstica.

Em relação ao desempenho financeiro da atividade de armazenagem e capatazia, desconsiderando depreciação e remuneração do capital, os aeroportos líderes em volume de carga obtiveram os resultados apresentados na Tabela 2, com destaque para os aeroportos Viracopos, Guarulhos, Galeão e Manaus, com os melhores resultados.

Alguns aeroportos apresentam prejuízos em seus TECA, tais como Brasília, Porto Alegre, Salvador e Fortaleza, sendo necessária uma exploração mais agressiva em relação aos terminais concorrentes das companhias aéreas e demais operadores logísticos, além de redução de custos e outras melhorias possíveis. Destaca-se que estes aeroportos apresentam altos índices de cargas com isenções tarifárias, o que agrava a situação de prejuízos da atividade de armazenagem, devido à grande concentração de organizações públicas e sem fins lucrativos.

Figura 1. Ligações aéreas cargas (à esquerda). Projeção Demanda em 2037 (à direita)

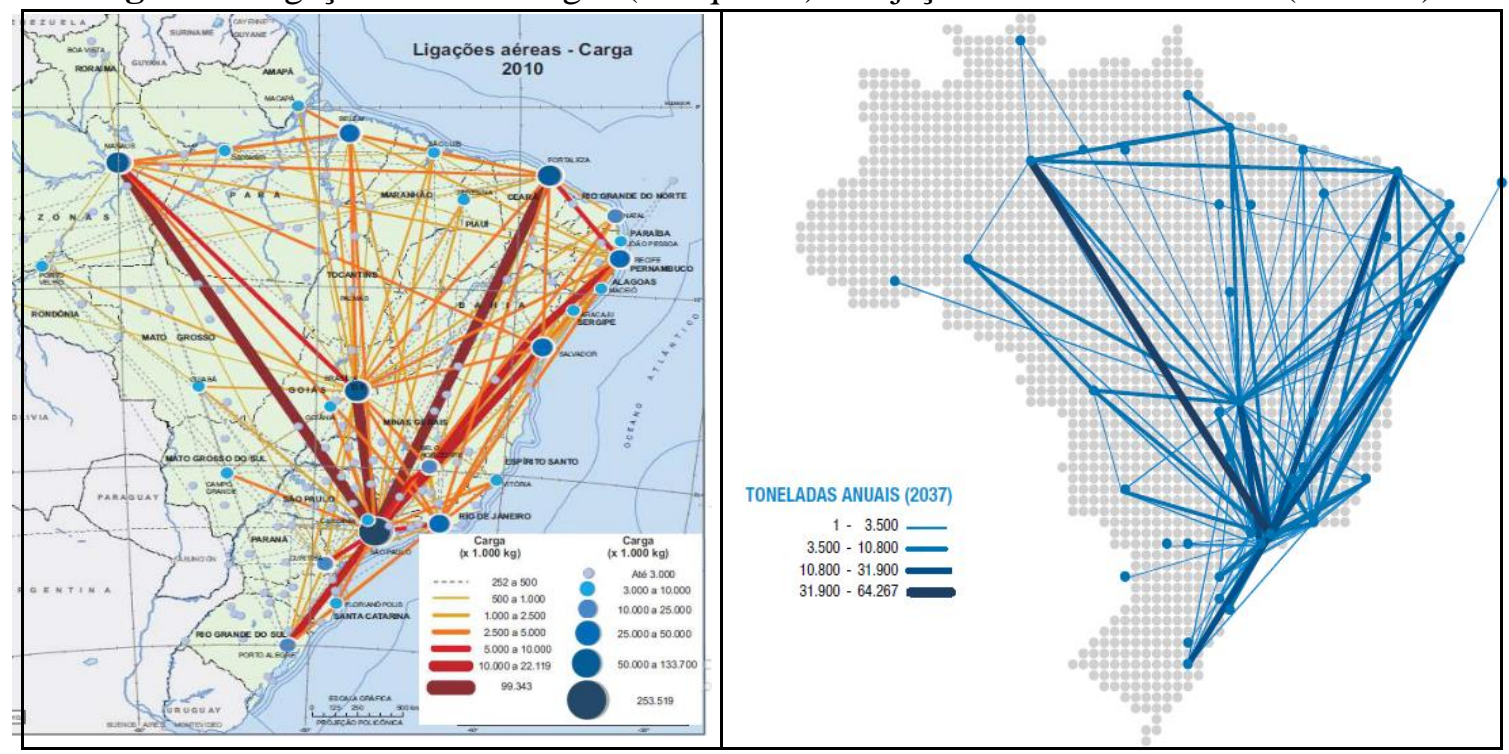

Fonte. BNDES (2010) e Ministério dos Transportes (2017)

Os aeroportos de Manaus, Porto Alegre e Guarulhos obtiveram um processamento maior de carga por metro quadrado. Em relação a produtividade não agregada, medida pela razão entre resultado e peso movimentado, Galeão se destacou com $\mathrm{R} \$ 813,91$ por tonelada, seguido por Curitiba com $\mathrm{R} \$ 647,60$, Viracopos com $\mathrm{R} \$$ 498,65 e Guarulhos com $\mathrm{R} \$ 303,67$.

Em 2010, a movimentação de carga nos 34 TECA da rede Infraero chegou a 1,139 milhões de toneladas, gerando um faturamento da logística de carga na ordem de $\mathrm{R} \$ 886,717$ milhões. Os 12 principais aeroportos movimentaram 1,109 milhões de toneladas e atingiram um faturamento de $\mathrm{R} \$ 856,445$ milhões em 2010.

Alguns terminais têm capacidade ociosa, conforme demonstrado na Figura 2, podendo processar maior volume de cargas, enquanto outros terminais encontram-se 
saturados, o que implica em aumento no tempo de desembaraço aduaneiro, alocação de carga em áreas fora de posições apropriadas e perda de mercadoria que necessitam refrigeração.

Tabela 2. Resultados de armazenagem e capatazia dos TECA em 2010 e isenções automáticas em reais

\begin{tabular}{|c|c|c|c|c|c|}
\hline AEROPORTO & Receita & $\begin{array}{c}\text { Resultado } \\
\text { (Receita-Custos) }\end{array}$ & $\begin{array}{c}\text { Isenções } \\
\text { (ton.) }\end{array}$ & \begin{tabular}{c|} 
Razão \\
Isenções/Import.
\end{tabular} & $\begin{array}{l}\text { Produtividade } \\
\text { Resultado/ton ) }\end{array}$ \\
\hline Guarulhos & $252.070 .090,00$ & $114.664 .682,00$ & $9.805,07$ & $6,93 \%$ & 303,67 \\
\hline Viracopos & $274.584 .344,00$ & $133.261 .276,00$ & $7.326,40$ & $4,31 \%$ & 498,65 \\
\hline Galeão & $119.253 .871,00$ & $65.169 .418,00$ & $57.092,37$ & $124,67 \%$ & 813,91 \\
\hline Confins & $20.647 .658,00$ & $4.642 .083,00$ & $11.972,12$ & $96,80 \%$ & 237,68 \\
\hline Brasília & $6.591 .352,00$ & $-5.229 .014,00$ & $28.364,84$ & $947,29 \%$ & $-636,92$ \\
\hline Manaus & $112.640 .323,00$ & $49.758 .231,00$ & 520,89 & $0,75 \%$ & 252,19 \\
\hline Porto Alegre & $17.181 .596,00$ & $-1.283 .286,00$ & $5.388,15$ & $42,70 \%$ & $-30,68$ \\
\hline Curitiba & $41.192 .933,00$ & $24.192 .905,00$ & 337,16 & $1,59 \%$ & 647,60 \\
\hline Recife & $9.559 .669,00$ & $-1.473 .580,00$ & 334,51 & $11,68 \%$ & $-46,63$ \\
\hline Salvador & $7.332 .002,00$ & $-3.806 .379,00$ & 47,71 & $1,32 \%$ & $-203,87$ \\
\hline Goiania & $6.141 .593,00$ & $4.155 .693,00$ & 389,62 & $2,20 \%$ & 233,84 \\
\hline Fortaleza & $6.832 .243,00$ & $-2.290 .955,00$ & 218,33 & $15,95 \%$ & $-185,81$ \\
\hline
\end{tabular}

Fonte. Infraero (2010) e ANAC (2011)

Figura 2. Capacidade operacional dos Terminais de Carga da INFRAERO

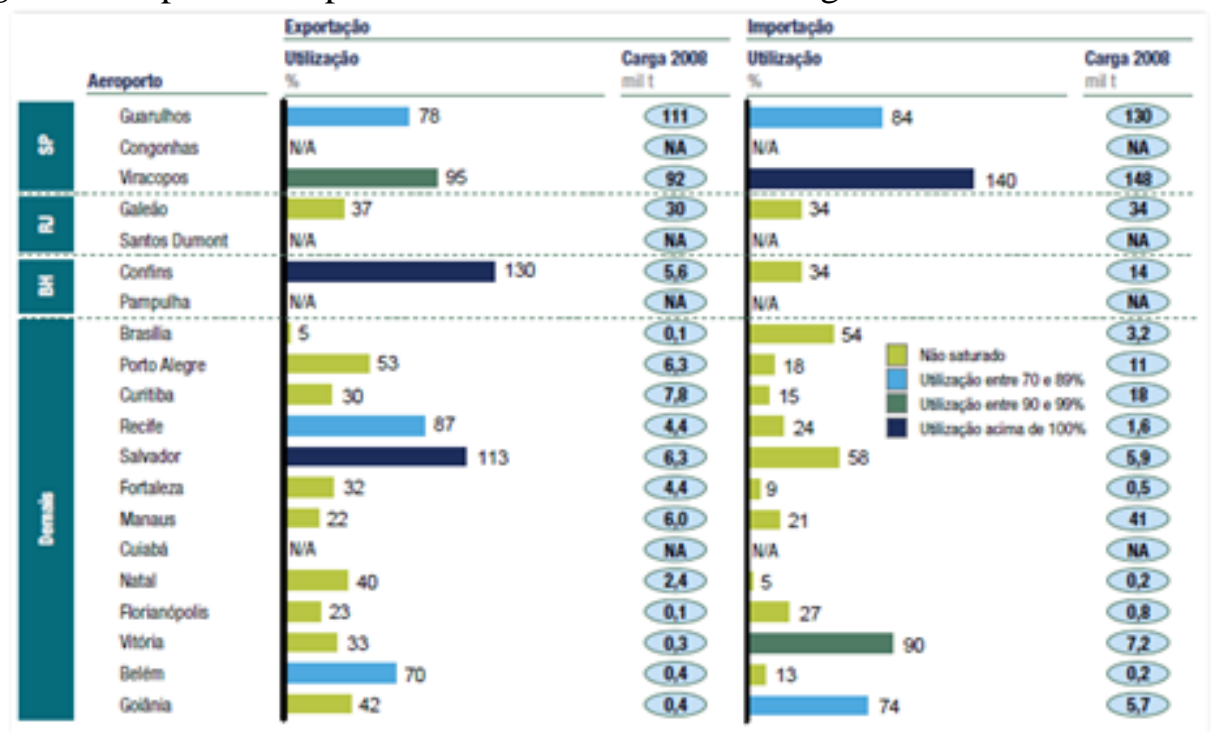

Fonte. Adaptado BNDES (2010)

Podem ser adotadas alternativas gerenciais para solução de gargalos pela redução de permanência da carga, celeridade nos processos de cargas em perdimento, automações de sistemas e capatazia, utilização e redistribuição de áreas de setores adjacentes (importação, exportação e doméstica) subutilizados, melhor utilização da altura disponível nos armazéns e espaços entre prateleiras, otimizar o tempo de turnaround e melhor distribuição do fluxo aéreo de aeronaves, entre outras alternativas menos onerosas.

\section{Características do Transporte Aéreo de Cargas}


O mercado de carga área é influenciado fortemente pelo transporte de passageiros. Segundo Gruenschlos (2005), as transportadoras de passageiros fornecem cerca de $75 \%$ da capacidade de transporte internacional de carga, ao passo que as companhias aéreas de carga detêm $25 \%$ da capacidade de porão. As primeiras detêm $85 \%$ da participação no mercado enquanto as cargueiras $15 \%$. A razão é que a combinação de passageiros com o transporte de carga é muitas vezes mais rentável devido aos efeitos de sinergia, fluxo bidirecional e custos operacionais já cobertos pela tarifa das passagens.

A capacidade dos decks inferiores representa cerca de $50 \%$ da capacidade total de carga global. As transportadoras de carga dedicadas (all cargo) têm mais flexibilidade do que as companhias aéreas de passageiros na escolha de aeroportos concorrentes, por ter a possibilidade de escolher os aeroportos que ainda não estão com saturação de slots e possibilidade de operação fora dos horários de pico (ZONDAG, 2006).

A carga de porão em aeronaves combinadas é vista como uma fonte complementar e oportunista de receita para operações de passageiros. No entanto, a carga de porão não vai substituir completamente as operações de cargueiros dedicados (all cargo); isto porque cargueiros dedicados oferecem confiabilidade e qualidade do serviço, não presentes por operações de carga de porão, principalmente porque as operações de carga são secundárias ao negócio de passageiros em várias companhias aéreas (AIRBUS, 2013).

De acordo com Zondag (2006), as principais características do transporte aéreo de carga são uma malha diversificada e densa de voos internacionais; a velocidade em distâncias longas e médias, a segurança superior aos demais modos e a alta confiabilidade no transporte. As desvantagens, principalmente econômicas, são os custos maiores, a dificuldade de se obter economias de escala devido às restrições de capacidade nas aeronaves cargueiras e a dificuldade de inserção em rotas que cobrem pequenas distâncias.

Como descrito na Tabela 3, os TECA com maior movimentação de carga estão associados aos maiores volumes de voos comerciais, operações com cargueiros e ligações aéreas (conexões) entre aeroportos, com exceção de Brasilia devido ao excesso de cargas isentas de tarifação, conforme já mencionado na Tabela 2.

Tabela 3. Movimento operacional dos aeroportos selecionados em 2010

\begin{tabular}{l|c|c|c|c}
\hline \multicolumn{1}{c|}{ Aeroporto } & $\begin{array}{c}\text { Mov. anual } \\
\text { pouso decolagem }\end{array}$ & $\begin{array}{c}\text { Mov. Anual } \\
\text { de cargueiros }\end{array}$ & $\begin{array}{c}\text { Companhias } \\
\text { Aéreas Operando }\end{array}$ & $\begin{array}{c}\text { Ligações aéreas } \\
\text { domésticas }\end{array}$ \\
\hline Guarulhos & 250.492 & 7.922 & 38 & 71.594 \\
\hline Viracopos & 74.472 & 6.668 & 16 & 9.437 \\
\hline Galeão & 122.943 & 3.062 & 28 & 68.117 \\
\hline Confins & 84.851 & 1.152 & 5 & 34.253 \\
\hline Brasília & 176.327 & 3.486 & 13 & 73.133 \\
\hline Manaus & 52.505 & 4.736 & 15 & 26.145 \\
\hline Porto Alegre & 90.625 & 1.003 & 12 & 37.057 \\
\hline Curitiba & 88.220 & 2.475 & 8 & 36.267 \\
\hline Recife & 77.325 & 1.123 & 9 & 38.300 \\
\hline Salvador & 114.940 & 3.809 & 9 & 48.850 \\
\hline Goiania & 64.678 & - & 4 & 32.749 \\
\hline Fortaleza & 62.570 & 1.165 & 9 & \\
\hline
\end{tabular}

Fonte. Anac (2010) e Infraero (2010) 
No mercado nacional, as maiores transportadoras aéreas em 2017, foram as empresas Latam, com participação de mercado de 28,82\%, seguidas pelas companhias aéreas Gol (23,96\%); Sideral Air Cargo (14,03\%); Avianca (13,35\%); Azul (9,90\%); ABSA $(9,62 \%)$, Modern $(0,16 \%)$, Rio Linhas Aéreas $(0,15 \%)$, de um montante total de 408.577,14 toneladas (ANAC, 2017). Nota-se que o transporte efetuado por cargueiros correspondeu a $23,96 \%$ do montante.

No caso da Empresa Brasileira de Correios e Telégrafos (ECT), o transporte, principalmente interestadual, conta com 13 linhas aéreas e 4 Terminais de Carga Aérea (Brasilia-DF, Salvador-BA, Guarulhos-SP e Galeão-RJ). Por não possuir aeronaves, a ECT passou a contratá-las por meio de empresas prestadoras de transporte de carga, intitulado de Rede Postal Aérea Noturna (RPN), no sistema denominado Full, que significa a disposição total do espaço dos aviões para a estatal (TCU, 2010).

Em 2010, oito empresas prestavam serviços no transporte de cargas da RPN: Rio e Total - que respondem por quase metade do total, Amazonaves; Air Brasil; América do Sul; Fretax; Trip e TWO, com 20 contratos vigentes, dos quais 17 são propriamente ditos da RPN, isto é, feitos no sistema Full, e 3 contratos não integrantes da RPN, ou seja, feitos por meio do aluguel do espaço de aeronaves, seja pertencente a empresa transportadora de carga ou integrante da Viação Área Comercial (TCU, 2010).

A capacidade de transporte da RPN é de $948.841 \mathrm{~kg}$ por trecho, ao custo, também por trecho, de $\mathrm{R} \$ 1.729 .205,09$. Em 2010, apenas os contratos com a empresa MTA eram operados pelo sistema não Full (aluguel de espaço nas aeronaves e pagamento pelo peso da carga transportada). Consta que aproximadamente 14\%, ou 943 toneladas, da quantidade de carga transportada pela ECT é feita por meio da RPN, enquanto que $86 \%$, ou 5.792 toneladas, são transportadas via malha de superfície (TCU, 2010).

\section{Localização de Hubs de Carga Aérea}

A partir da década de 1960 houve forte atuação regulatória do Estado na aviação civil brasileira, determinando a ligação invariável entre as cidades em um sistema ponto-a-ponto, garantindo uma maior cobertura regional e ausência de competição entre as empresas aéreas. Nas décadas de 1970 e 1980 a regulação foi forte, havendo maior liberação e estímulo à competição apenas a partir da década de 1990.

Esse processo de liberação ocasionou um crescimento expressivo do transporte de carga aérea no Brasil, atingindo uma participação cada vez maior na balança comercial. Esse crescimento é explicado principalmente pelo crescimento no transporte aéreo de passageiros no final da década de 1990 e substituição do sistema ponto-a-ponto pelo sistema centro-raio (hub-and-spoke system), que consiste na escolha de aeroportos centrais de conexão (hubs), ligando-se aos aeroportos regionais (spoke), potencializando, dessa forma, o número de voos e alocando as aeronaves para voos entre os aeroportos hubs e os aeroportos regionais.

A característica mais importante de um hub é o tráfego direto de ligação. Sem várias conexões a companhia aérea não será capaz de lucrar suficientemente e aproveitar o efeito de sinergia que este sistema pode oferecer, alcançando ganhos de escala, por meio dos efeitos da conexão em rede, redução tarifária, eficácia em custo e tempo.

Uma companhia aérea no sistema hub tem a possibilidade de oferecer conexões com pouca demanda, porque o número de conexões de rede pode ser expandido com custos relativamente baixos, ou seja, fazendo-se várias conexões antes de se chegar ao 
destino final proporciona custos mais baixos do que em uma conexão direta (BLUNCK, 2005).

Um fator chave que tem de ser considerado na implementação de um hub é o fato que hubs aéreos podem ser caros para construir e operar. Consequentemente, as pequenas companhias aéreas em particular têm de examinar se há recursos financeiros suficientes para realizar um projeto tão grande e se seus fluxos de carga pagarão o investimento inicial e a manutenção do negócio. A eficácia de um hub cresce com a disponibilidade de infraestrutura e o fluxo de carga aérea, no caso de uma operação de carga aérea de baixo volume - onde as economias de escala só podem ser alcançadas numa extensão limitada - a rede tradicional linear pode ser mais econômica (DOGANIS, 1985).

Segundo Oktal e Ozger (2013), os custos de transporte são maiores influenciadores para a projeção de hubs; sendo que os principais fatores que afetam hubs de carga aeroportuários são as características setoriais, a variedade de aeronaves operando, custos por viagem, disponibilidade de pistas e de carga e a continuidade do tráfego (demanda).

Um aeroporto que não tem tráfego de carga regular por causa de variações sazonais na demanda pode ser escolhido como um hub, mas isso pode aumentar os custos operacionais. A construção de uma nova pista ou aumento da capacidade de uma já existente requer investimentos consideráveis. Além disso, o aeroporto designado como hub deve ter pista suficiente disponível para receber grandes aviões de carga e alta densidade de tráfego - expresso em Kg/m3 (OKTAL; OZGER, 2013).

O transportador deve decidir sobre a viabilidade de implementação de uma rota. É definido o número e localização dos depósitos, bem como os hubs que vão ser utilizados, pois são fatores-chave, tanto para a logística como para os custos da rede. Para ser capaz de tomar uma boa decisão, dados sobre os fluxos de mercadorias esperadas são essenciais para os cálculos necessários da rede e futuro dimensionamento.

A concorrência por parte das empresas aéreas ocorre principalmente por áreas de hangar e por slots. Um aeroporto hub apresenta dezenas de operadores e transportadores, sendo fundamental que as expansões ocorram não somente nos terminais de passageiros e carga, mas também na disponibilidade de hangares, áreas comerciais e horários para pouso e permanência.

Os fatores de localização, tais como nível de renda, nível de atividade econômica expressos pelo PIB e fatores de serviço, como celeridade do desembaraço aduaneiro, também influenciam o potencial logístico aeroportuário. No que diz respeito a essas variáveis, os aeroportos selecionados apresentam os valores da Tabela 4.

$\mathrm{Na}$ Tabela 5 é apresentada a infraestrutura dos aeroportos selecionados a partir de dados atuais e o processamento de carga dado pela razão entre toneladas e metro quadrado dos TECAS, fatores essenciais para atratividade de companhias aéreas e operadores logísticos. Os aeroportos de Guarulhos, Viracopos e Galeão são os que possuem maiores áreas dos TECA, mas Manaus e Porto Alegre apresentaram um melhor processamento de carga com 17,61 e 10,58 toneladas por metro quadrado, respectivamente.

Há fortes barreiras para os transportadores entrarem no mercado brasileiro devido ao domínio de hubs, grande aporte de capital necessário, economia de escala das empresas com grande frota, altos investimentos em sistemas de informações, restrições de infraestrutura e domínio de slots, exigência de capital nacional, a vedação à 
cabotagem por empresas estrangeiras e excesso de burocracia exigida para a abertura de novas empresas, entre outros.

Tabela 4. Variáveis de localização e serviço dos aeroportos selecionados

\begin{tabular}{l|c|c|c|c}
\hline AEROPORTO & $\begin{array}{c}\text { Conexões } \\
\text { empresariais }\end{array}$ & $\begin{array}{c}\text { PIB da rede } \\
\text { de influência }\end{array}$ & $\begin{array}{c}\text { PIB per capita } \\
\text { da rede }\end{array}$ & $\begin{array}{c}\text { Tempo desembaraço } \\
\text { Aduana (hora) } \\
\text { canal verde }\end{array}$ \\
\hline Guarulhos & $27.591,00$ & $871.293 .264,00$ & $16.890,00$ & 7,55 \\
\hline Viracopos & $4.692,00$ & $90.276 .616,00$ & $18.405,00$ & 4,08 \\
\hline Galeão & $13.299,00$ & $309.075 .787,00$ & $14.895,00$ & 12,96 \\
\hline Confins & $5.631,00$ & $160.464 .785,00$ & $9.582,00$ & 4,18 \\
\hline Brasília & $6.523,00$ & $148.520 .823,00$ & $15.342,00$ & 11,01 \\
\hline Manaus & $1.517,00$ & $36.064 .497,00$ & $10.363,00$ & 5,24 \\
\hline Porto Alegre & $5.737,00$ & $209.042 .241,00$ & $13.661,00$ & 6,61 \\
\hline Curitiba & $5.547,00$ & $211.981 .322,00$ & $13.102,00$ & 8,01 \\
\hline Recife & $3.329,00$ & $101.101 .402,00$ & $5.356,00$ & 9,24 \\
\hline Salvador & $2.163,00$ & $104.996 .166,00$ & $6.428,00$ & 13,23 \\
\hline Goiania & $2.410,00$ & $60.194 .471,00$ & $9.393,00$ & 11,47 \\
\hline Fortaleza & $2.291,00$ & $95.945 .410,00$ & $4.664,00$ & 9,32 \\
\hline
\end{tabular}

Fonte. IBGE (2007) e Receita Federal do Brasil (2018)

Tabela 5. Variáveis de Infraestrutura dos aeroportos selecionados

\begin{tabular}{l|c|c|c|c|c|c|c}
\hline $\begin{array}{c}\text { Aeroport } \\
\text { o }\end{array}$ & $\begin{array}{c}\text { Posiçõe } \\
\text { s } \\
\text { pátio }\end{array}$ & $\begin{array}{c}\text { Área } \\
\text { pátio } \\
\text { aeronaves }\end{array}$ & $\begin{array}{c}\text { Área } \\
\text { TECA } \\
\text { Importaç }\end{array}$ & $\begin{array}{c}\text { Área } \\
\text { TECA } \\
\text { Exportaç }\end{array}$ & $\begin{array}{c}\text { Area } \\
\text { TECA } \\
\text { Domésti }\end{array}$ & $\begin{array}{c}\text { Comprim. } \\
\text { linear } \\
\text { total }\end{array}$ & $\begin{array}{c}\text { Processam. } \\
\text { (Ton./área) }\end{array}$ \\
\hline Guarulho & 100 & $468.110,0$ & $46.092,0$ & $22.887,0$ & $4.990,00$ & $6.700,00$ & 10,03 \\
\hline Viracopo & 35 & $145.800,0$ & $60.035,0$ & $15.560,0$ & $5.405,00$ & $3.240,00$ & 3,08 \\
\hline Galeão & 73 & $712.895,0$ & $31.299,0$ & $11.560,0$ & - & $7.180,00$ & 1,48 \\
\hline Confins & 35 & $86.000,00$ & $7.768,00$ & 696,00 & 696,00 & $3.000,00$ & 3,96 \\
\hline Brasília & 69 & $57.113,00$ & $5.908,00$ & 307,00 & 553,00 & $6.740,00$ & 3,47 \\
\hline Manaus & 47 & $142.000,0$ & $32.695,0$ & $4.128,00$ & $2.478,00$ & $2.700,00$ & 17,61 \\
\hline P. Alegre & 29 & $136.272,0$ & $3.361,50$ & $1.130,50$ & $1.016,25$ & $2.280,00$ & 10,58 \\
\hline Curitiba & 26 & $90.286,25$ & $10.764,0$ & $2.040,00$ & $2.156,00$ & $4.016,00$ & 3,25 \\
\hline Recife & 21 & $139.616,0$ & $4.541,00$ & 625,00 & $2.472,00$ & $3.007,00$ & 5,33 \\
\hline Salvador & 42 & $211.000,0$ & $3.247,55$ & 888,45 & 743,00 & $4.521,00$ & 6,72 \\
\hline Goiania & 29 & $37.445,00$ & $2.067,00$ & 41,34 & - & $2.500,00$ & 3,56 \\
\hline Fortaleza & 20 & $152.857,0$ & $5.236,00$ & $2.233,00$ & 579,00 & $2.545,00$ & 4,95 \\
\hline
\end{tabular}

\section{Variáveis de Competitividade Logística Aeroportuária}

Um centro logístico deve possuir empreendimentos e infraestruturas relativas ao transporte, logística e distribuição de mercadorias. Segundo Boudoin (1996), uma plataforma logística engloba três componentes: 1) serviços gerais: áreas que englobam recepção, informação, acomodação e alimentação, bancos, agência de viagens, estacionamento, abastecimento e reparos, serviços de alfândega, administração e comunicação; 2) transportes: que agrupa infraestruturas de grandes eixos de transportes e terminais de integração multimodais; 3) espaço para operadores logísticos e suporte para serviços de fretamento, corretagem, assessoria comercial e aduaneira, aluguel de equipamentos, armazenagem, transporte e distribuição.

Kasarda (2004) desenvolveu o conceito do Global Transpark (GTP). Como consequência, o primeiro GTP do mundo foi planejado em 1994 com base em um pequeno aeroporto em Kinston, na Carolina do Norte (EUA) e sua construção iniciada em 1998. Em 2001, a pista original foi estendida para duas pistas paralelas de 3.505 e 3.962 metros. No sítio de 6.364 hectares, planejaram-se complexos multimodais de 
apoio às empresas de fabricação, distribuição e transporte e os impostos e zonas de comércio exterior isentos (SIT, 2004).

Em janeiro de 2002, o primeiro GTP - facilidade para carga - de $58.000 \mathrm{~m}^{2}$ foi concluído e colocado em uso. Como resultado, naquele ano, o GTP movimentou 80 milhões de quilos de carga aérea industrial, um aumento de $600 \%$ em relação a 2001 . O plano diretor para o segundo GTP localizado em U-Taphao na Tailândia foi aprovado em 1998, e sua construção começou em 2000. Em Mckenburg, Alemanha, outro plano GTP foi elaborado no final de 2000 (SIT, 2004).

Wong, Chung e Hsu (2016) utilizaram cinco aspectos para analisar a competitividade aeroportuária: 1) Comércio Internacional; 2) Frequência de voo; 3) Distribuição de rotas; 4) Distribuições de transportadoras nacionais e estrangeiras; 5) Localização. O autor buscou investigar a competitividade, hierarquia e potencial competitivo dos aeroportos em termos de demanda e suprimentos no mercado de carga, por meio da centralidade do autovetor e aplicação de agrupamento k-means e diferença de médias entre os grupos em cada critério.

De acordo com Chao e Yu (2013), as medidas utilizadas em estudos anteriores podem ser divididas em três dimensões: 1) Capacidade de transporte aéreo; 2) Instalações e operações aeroportuárias; 3) Desenvolvimento econômico. Entre as dimensões, a capacidade de transporte aéreo é dividida em número de companhias aéreas que operam em aeroportos, passageiros e voos de carga e frotas, bem como cidades de origem e destino de companhias aéreas nacionais.

A dimensão das instalações e operações aeroportuárias compreende medidas que incluem taxas aeroportuárias, horário de funcionamento, tempos de desembaraço de carga e cotas para uso da pista. As medidas para a dimensão do desenvolvimento econômico incluem o crescimento anual de carga e o PIB e a renda nacional dos países onde os aeroportos estão localizados. Chao e Yu (2013) pretenderam desenvolver um modelo de avaliação quantitativa para analisar a competitividade da carga aérea de aeroportos por meio do método Delphi e para avaliação quantitativa da competitividade questionários de pesquisa à especialistas.

Segundo Senguttuvan (2006), são cinco variáveis gerais que determinam a competitividade aeroportuária: 1) Fatores espaciais ou desenvolvimento regional crescente em torno do aeroporto com surgimento de zonas de comércio internacional, logística e centros de convenções, zonas econômicas e comerciais com isenção tributária, complexos industriais relacionados com a aviação e outras instalações que permitam o crescimento de um aeroporto; 2) Fatores de instalação ou o nível de instalações aeroportuárias e expansão de instalações em aeroportos existentes para aumento da capacidade de movimentação de carga aérea; 3) Fatores de demanda ou o nível de demanda origem-destino dos volumes de tráfego para desenvolvimento de redes hub-spoke; 4) Fatores de serviço, que consistem no nível de serviços disponibilizados aos usuários, tipos de operações aeroportuárias e nível das taxas aeroportuárias; 5) Fatores gerenciais ou econômicos, como custos de operação do aeroporto, produtividade e a estrutura de receitas.

Do ponto de vista do transportador de carga aérea, Gardiner (2005) avaliou que os principais fatores para seleção de um aeroporto seria, na ordem de importância: operação noturna, custos reduzidos, reputação cargueira do aeroporto, demanda origem destino local, influência de agentes de cargas, acesso viário do aeroporto, nível de serviço do desembaraço aduaneiro, incentivos financeiros do aeroporto, tempo de entrega viário da mercadoria aos principais mercados. Seu objetivo foi identificar e 
avaliar a gama de fatores que influenciam a escolha do aeroporto por companhias aéreas operadoras de carga, utilizando análise hierárquica de variáveis numa amostra de 118 companhias aéreas.

Para Larrodé et al. (2018), os principais fatores de atratividade logística de um aeroporto são em ordem de importância: taxas aeroportuárias, Custos de manuseio definidos pelo número de agentes de manuseio no aeroporto; segurança de carga no sítio aeroportuário; volume origem destino; quantidade de companhias aéreas em operação, presença de operadores logísticos, tecnologia de manuseio de carga, tecnologia do armazém de carga - capacidade e automação; tecnologias de balanceamento de carga no armazém e nota de entrega eletrônica, tecnologia de segurança e verificação de cargas; restrição de ruídos. Seu objetivo foi avaliar a capacidade de um aeroporto para atrair operações de carga e companhias aéreas de carga pelo método AHP.

McKinnon (2011) identificou as características específicas relacionadas à competitividade de aeroportos, tais como: 1) Localização - aeroportos localizado mais próximos de operadores logísticos/agentes de carga têm vantagens de custo e de tempo; 2) Infraestrutura aeroportuária capacidade das pistas, transporte nas conexões e instalações apropriadas do terminal; 3) Taxas aeroportuárias; 4) Regras aduaneiras e encargos; 5) Congestionamento e a falta de disponibilidade de faixas horárias (slots); 6) Disponibilidade e qualidade dos agentes de carga; 7) Restrições ambientais, tais como os limites de ruído e toques de recolher noturnos; 8) Restrições regulamentares.

Para Lee (2007), as variáveis para um hub de carga se apresentam da seguinte forma: 1) Localização: localização geográfica (se ele está dentro do raio de voo de 4 horas, se está na presença de uma zona de livre porto), infraestrutura logística local; 2) Demanda: tamanho do mercado e potencial de crescimento, companhias de bandeira, provedores de serviços de logística, por exemplo, a Fedex, UPS, DHL; 3) Custo: taxas de utilização de aeroportos, tais como taxa de aterrisagem, taxa de estacionamento, taxa de serviço de carga, custo do trabalho e preço do terreno/aluguéis para instalação de hangares; 4) Infraestrutura: capacidade das pistas, pátios, terminal de carga, capacidade de expansão da área do terminal, tecnologia, qualidade do mercado de trabalho; 5) Governo: acordo de liberdade de voo, zona de livre comércio, incentivos fiscais e estabilidade política.

Zhang (2003) descreveu os fatores de competitividade da indústria da carga aérea na perspectiva aeroportuária, nos aspectos localização geográfica, custo, tempo de entrega, infraestrutura, intermodalidade, política de aviação internacional. Considerando a localização geográfica como fator minimizador das distâncias totais origem-destino aos principais mercados, o que permite a operação de aeronaves de grande capacidade. Entre os custos estão tarifas aeroportuárias e custos de manuseio. Em relação ao tempo de entrega considera a frequência de voo, quantidade de companhias aéreas presentes no aeroporto e agentes de carga. A variável infraestrutura engloba a capacidade do aeroporto, malha rodoviária $\mathrm{e}$ infraestrutura tecnológica. $\mathrm{O}$ autor discute as características e tendências da carga aérea e propõe uma análise dos fatores competitivos da indústria de carga aérea, por meio da análise descritiva e conceitual das varáveis.

No presente estudo foram selecionadas 22 variáveis, com disponibilidade de dados pelos órgãos reguladores do setor, conforme ilustrado na Figura 3. 
Figura 3. Variáveis selecionadas na pesquisa

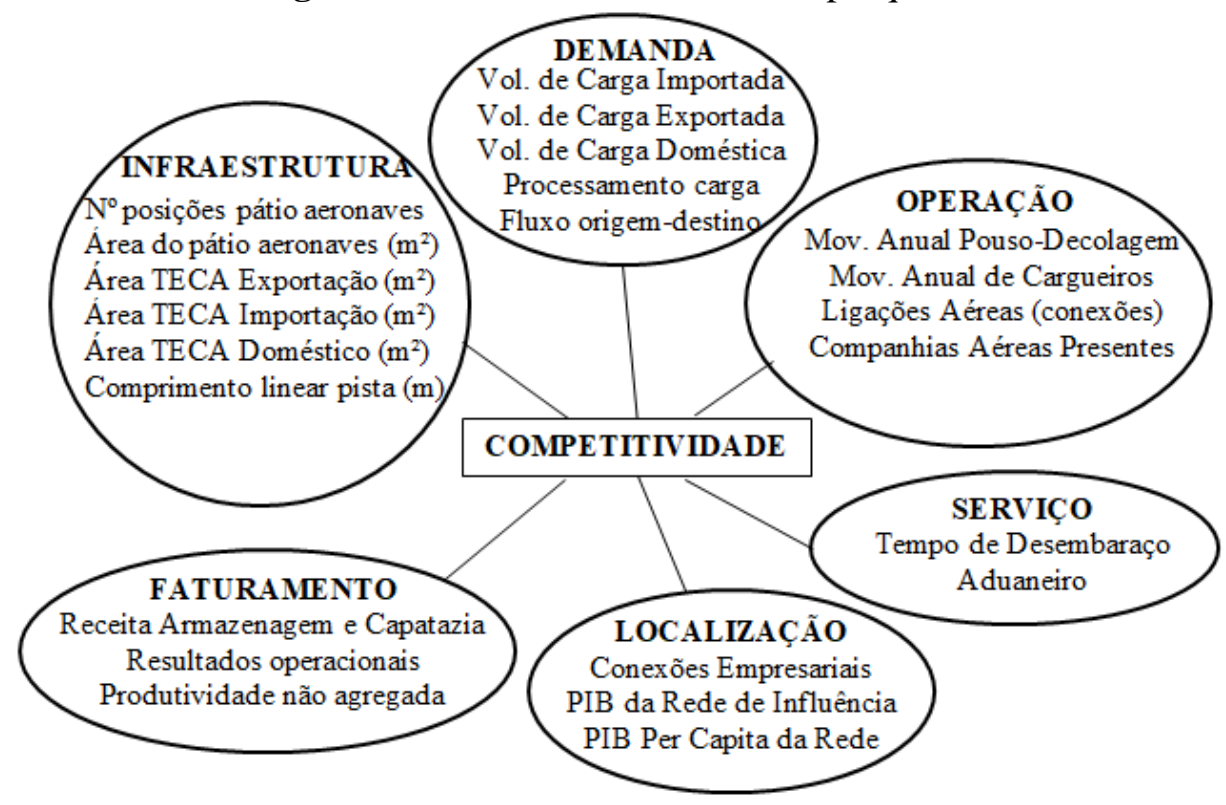

Fonte. Elaborada pelos autores

\section{Procedimentos Metodológicos}

Foi utilizada a técnica de pesquisa descritiva, do tipo documental e bibliográfica, com levantamento bibliográfico em artigos científicos sobre o tema para definição das variáveis de estudo e pesquisa documental para coletar dados secundários disponíveis em relatórios gerenciais e anuários de órgãos vinculados a aviação civil, como INFRAERO, ANAC, Concessionárias, e outros órgãos afins, tais como IBGE e Receita Federal do Brasil. Para tratamento dos dados foi utilizada a técnica Análise de Componentes Principais (ACP), de forma a se obter a similaridades entre os aeroportos e definição de quais variáveis retém a maior quantidade de informações que explicam o conjunto de dados.

Cada componente principal é uma combinação linear das variáveis originais e tem sua variância como medida da quantidade de informação. As etapas da ACP consistem em: 1) Padronização dos dados e cálculo do vetor médio dos dados, 2) Subtrair a média de todos os itens de dados; 3) Calcular a matriz de covariância e 4) Calcular os autovalores e autovetores da matriz de covariância, e 5) análise de agrupamentos (clusters) utilizando a distância euclidiana e agrupamento médio aos pares.

Padronização é dada por:

$$
Z_{i j}=\frac{X i j-X j}{S_{j}}
$$

A matriz de dados tem " $p$ " atributos $(j=1,2, \ldots, p)$ e tem " $n$ " objetos $(i=1,2, \ldots, n)$ Onde:

i: aeroportos, tal que $i=1,2, \ldots, n$;

$\mathrm{j}$ : fatores, tal que $\mathrm{j}=1,2, \ldots, \mathrm{p}$;

$\mathrm{Xj}$ : valor do $\mathrm{j}$-ésimo fator para o i -ésimo aeroporto; 
- $\quad \mathrm{X} \mathrm{j}$ Média dos dados com atributo “j”.

$\mathrm{Sj}$ : variância dos dados com atributo "j".

A matriz de covariância para $\mathrm{M}$ amostras de vetores com vetor médio é dada por:

$$
C x=\frac{1}{M} \sum_{I=1}^{M} x_{i} x_{i}^{T}-m_{i} m_{i}^{T}
$$

É chamado de $\mathrm{v}$ o autovetor de uma matriz quadrada $\mathrm{M}$ se Mv for múltiplo de v, ou seja, $\lambda v$. Assim, $\lambda$ é o autovalor de $\mathrm{M}$ associado ao autovetor $\mathrm{v}$, já $\mathrm{v}$ é um autovetor da matriz $\mathrm{M}$ se, e somente se:

$$
\mathrm{Mv}=\lambda \mathrm{V} \rightarrow(\mathrm{M}-\lambda \mathrm{I}) \mathrm{V}=0
$$

Após a obtenção dos valores por componentes principais, foi realizada a normalização dos valores das três principais componentes, que corresponderam a um grau de explicação $85,52 \%$ dos dados, pela técnica dos valores máximos e mínimos para obtenção do peso médio de cada variável.

$$
\left(Z_{i}^{k}\right)_{N}=\frac{Z_{i}^{k}-Z_{\text {min }}^{k}}{Z_{i}^{k} \max -Z_{\min }^{k}}
$$

Para se obter o índice de competitividade logística, foi utilizada a fórmula de cálculo da produtividade agregada e posteriormente a fórmula da eficiência, que corresponde à razão entre as produtividades de cada unidade com a máxima produtividade observada, onde esta apresenta valor 1 .

Onde:

$$
\mathrm{P}=\frac{Y}{X}=\frac{u_{1} \cdot y_{1}+u_{2} \cdot y_{2}+\ldots+u_{n} \cdot y_{n}}{v_{1} \cdot x_{1}+v_{2} \cdot x_{2}+\ldots+v_{m} \cdot x_{m}}
$$

$P$ : produtividade;

$Y$ : output agregado;

ui: peso do $i$-ésimo output;

yi: $i$-ésimo output;

$X$ : input agregado;

$v \mathrm{j}$ : pesos do $j$-ésimo input; e

Onde:

$$
\varphi=\frac{P k}{P \max }
$$

$\varphi \mathrm{k}$ : eficiência da $k$-ésima unidade;

$P k$ : produtividade da $k$-ésima unidade; e $P^{\max }$ : produtividade máxima entre os $\mathrm{Pk}$.

Para se verificar a dissimilaridade entre aeroportos foi utilizada a distância euclidiana. Considerando o vetor aleatório $\mathrm{X}_{j}{ }^{i}=[\mathrm{Xj} 1, \mathrm{Xj} 2, \ldots, \mathrm{Xjp}]$, com $\mathrm{p}$ variáveis para cada elemento $\mathrm{j}$ dos $\mathrm{n}$ elementos. Os elementos são comparados em cada variável $\mathrm{i}$.

$d(X l, X k)=\left[(X l-X k)^{\prime}(X l-X k)\right]=\left[\sum_{I=1}^{p}(X l i-X k i)^{2}\right]^{1 / 2}$

\section{Resultados}

A partir das informações descritas nas Tabelas anteriores, foi utilizado o software $\mathrm{R}$ versão 3.4.3, chegando-se às matrizes e gráficos abaixo. Os resultados apontam que as variáveis de maior relevância são na ordem de importância: fluxo total da carga origem e destino doméstico, movimento anual pouso-decolagem, quantidade 
de posições no pátio de aeronaves, quantidade de ligações (conexões) aéreas domésticas.

A partir da análise das Figuras 4 e 5, percebe-se que a primeira componente principal indicou que as variáveis área teca exportação, companhias aéreas operando, vol. anual TECA carga exportação (ton.) e faturamento TECA (cargas+serviços) são as que possuem maior informação sobre os dados. Os aeroportos Guarulhos, Viracopos, Galeão e Manaus são os que mais se aproximam das variáveis de maior explicação da base de dados. Ressalta-se que os vetores, mais próximos ao eixo pontilhado vertical, são os que explicam mais fortemente o conjunto de dados.

Conforme as Figuras 4 e 5, e dados de correlações entre as variáveis, tempo de desembaraço aduaneiro, processamento de carga e produtividade TECA são as que apresentam menores correlações com as demais variáveis, tendo em vista que são variáveis calculadas a partir de quantitativos de outras variáveis, e cujos valores servem para análise geral, mas que não respondem significativamente para explicar o conjunto de dados.

Pela segunda componente principal, nota-se que as variáveis "área do pátio aeronaves", " $\mathrm{n}$ ( posições pátio aeronaves", "movimento anual pouso-decolagem", "comprimento linear total de pistas", "tempo desembaraço aduana" e "ligações aéreas domésticas" concentram a maior explicação sobre os dados.

Pela terceira componente principal, nota-se que as variáveis mais relevantes são processamento de carga, volume anual TECA carga doméstica, fluxo carga origem e destino doméstico, área TECA doméstico, movimento anual de cargueiros e movimento anual pouso decolagem.

Figura 4. Relação dos aeroportos em relação a componente principal 1 e 2

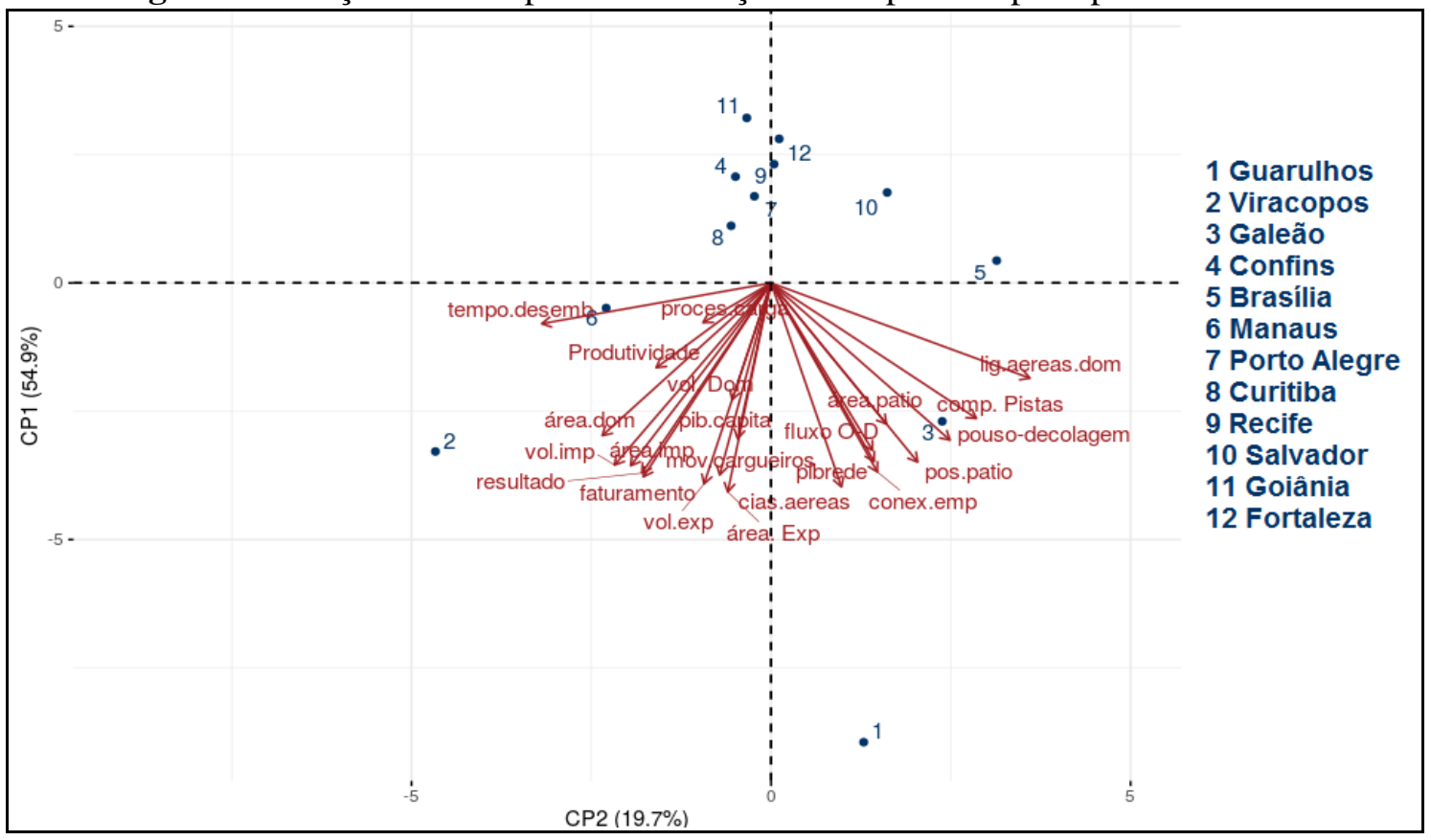

Fonte. Dados da pesquisa 
Figura 5. Relação dos aeroportos em relação a componente principal 1 e 3

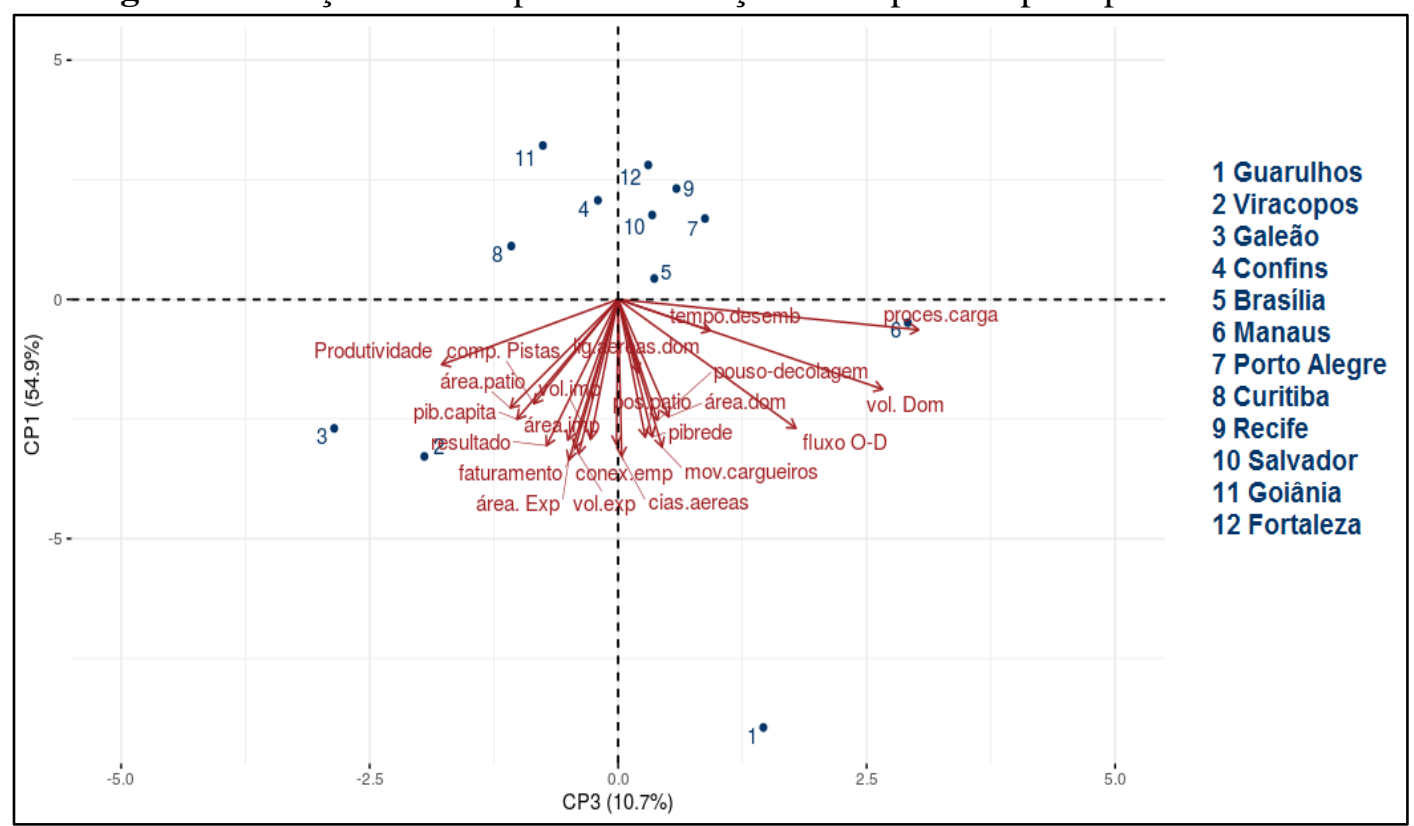

Fonte. Dados da pesquisa

$\mathrm{Na}$ análise de componentes principais verificou-se que $94 \%$ da variabilidade total dos dados é explicada pelas 5 primeiras componentes. Utilizando essas componentes para retratar todo o banco de dados, obteve-se o agrupamento dos aeroportos a partir dos autovetores, utilizando-se como método o agrupamento médio dos pares e a distância euclidiana como coeficiente de semelhança, chegando-se às coordenadas espaciais na Tabela 6.

Tabela 6. Coordenadas no espaço referente as 3 primeiras componentes

\begin{tabular}{l|c|c|c}
\hline AEROPORTO & CP1 & CP2 & CP3 \\
\hline Guarulhos & $-8,95$ & 1,29 & 1,46 \\
\hline Viracopos & $-3,28$ & $-4,67$ & $-1,95$ \\
\hline Galeão & $-2,70$ & 2,38 & $-2,86$ \\
\hline Confins & 2,07 & $-0,49$ & $-0,20$ \\
\hline Brasilia & 0,44 & 3,14 & 0,36 \\
\hline Manaus & $-0,49$ & $-2,29$ & 2,91 \\
\hline Porto & 1,69 & $-0,23$ & 0,87 \\
\hline Curitiba & 1,11 & $-0,56$ & $-1,08$ \\
\hline Recife & 2,32 & 0,04 & 0,59 \\
\hline Salvador & 1,76 & 1,62 & 0,34 \\
\hline Goiânia & 3,22 & $-0,34$ & $-0,76$ \\
\hline Fortaleza & 2,81 & 0,11 & 0,30 \\
\hline \multicolumn{4}{|c}{ Fonte. Dados da pesquisa }
\end{tabular}

A partir das novas coordenadas, pôde-se realizar um agrupamento hierárquico dos aeroportos, utilizando como método o agrupamento médio dos pares e a distância euclidiana como coeficiente de semelhança, conforme dados da matriz frenética demonstrada na Tabela 7 e ilustradas nas Figuras 6 e 7.

Ao definir a distância média em 4 (ponto médio do dendograma - Figura 6), obteve-se 6 grupos de aeroportos, onde 5 são unitários. Os aeroportos de Guarulhos, 
Viracopos, Galeão, Manaus e Brasilia foram classificados nos grupos de 1 a 5 (grupos unitários) os aeroportos restantes foram todos agrupados no grupo 6.

O fato de 7 aeroportos pertencerem ao grupo 6 significa que estes aeroportos têm valores absolutos semelhantes em relação as variáveis em estudo e, consequentemente, possuem semelhanças em relação a participação de mercado e características setoriais e de infraestrutura.

Tabela 7. Matriz Frenética

\begin{tabular}{c|c|c|c|c|c|c|c|c|c|c|c|c}
\hline & Guar. & Vira. & Gale. & Conf. & Bras. & Man. & P.A. & Cur. & Rec. & Sal. & Goi. & For. \\
\hline Guarulhos & 0 & & & & & & & & & & & \\
\hline Viracopos & 9,13 & 0 & & & & & & & & & & \\
\hline Galeão & 8,13 & 7,81 & 0 & & & & & & & & & \\
\hline Confins & 11,29 & 7,32 & 6,78 & 0 & & & & & & & & \\
\hline Brasilia & 10,05 & 9,01 & 6,19 & 4,98 & 0 & & & & & & & \\
\hline Manaus & 9,70 & 6,67 & 7,79 & 5,30 & 7,08 & 0 & & & & & & \\
\hline Porto & 10,76 & 7,50 & 6,74 & 1,27 & 4,64 & 4,37 & 0 & & & & & \\
\hline Curitiba & 10,54 & 6,36 & 5,65 & 1,39 & 4,89 & 5,24 & 2,06 & 0 & & & & \\
\hline Recife & 11,39 & 7,94 & 6,83 & 1,33 & 4,54 & 4,79 & 0,85 & 2,17 & 0 & & & \\
\hline Salvador & 10,96 & 8,47 & 5,91 & 3,10 & 2,95 & 5,40 & 2,62 & 3,18 & 2,18 & 0 & & \\
\hline Goiânia & 12,50 & 8,10 & 7,10 & 1,64 & 5,38 & 5,89 & 2,30 & 2,20 & 1,67 & 2,99 & 0 & \\
\hline Fortaleza & 11,90 & 8,25 & 7,00 & 1,52 & 4,73 & 5,19 & 1,43 & 2,35 & 0,60 & 2,23 & 1,22 & 0 \\
\hline
\end{tabular}

Fonte. Dados da pesquisa

Figura 6. Dendograma

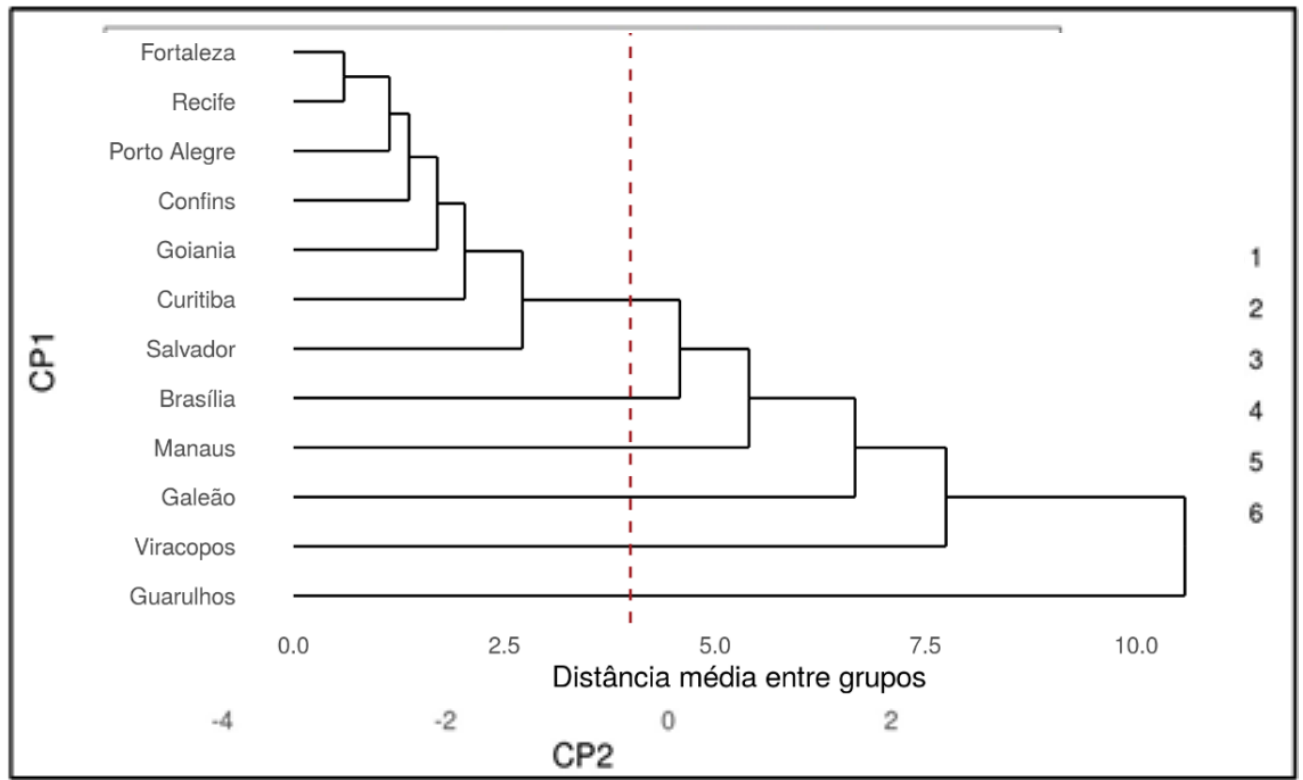

Fonte. Dados da pesquisa

A partir dos valores absolutos dos autovetores dos três primeiros componentes principais, foi realizada a normalização dos valores pela técnica dos valores máximos e mínimos, de forma a se obter os pesos médios para cada variável, a ser multiplicado pelos valores absolutos de cada variável, conforme demonstrado na Tabela 8. 
Figura 7. Agrupamento com utilização de média 4

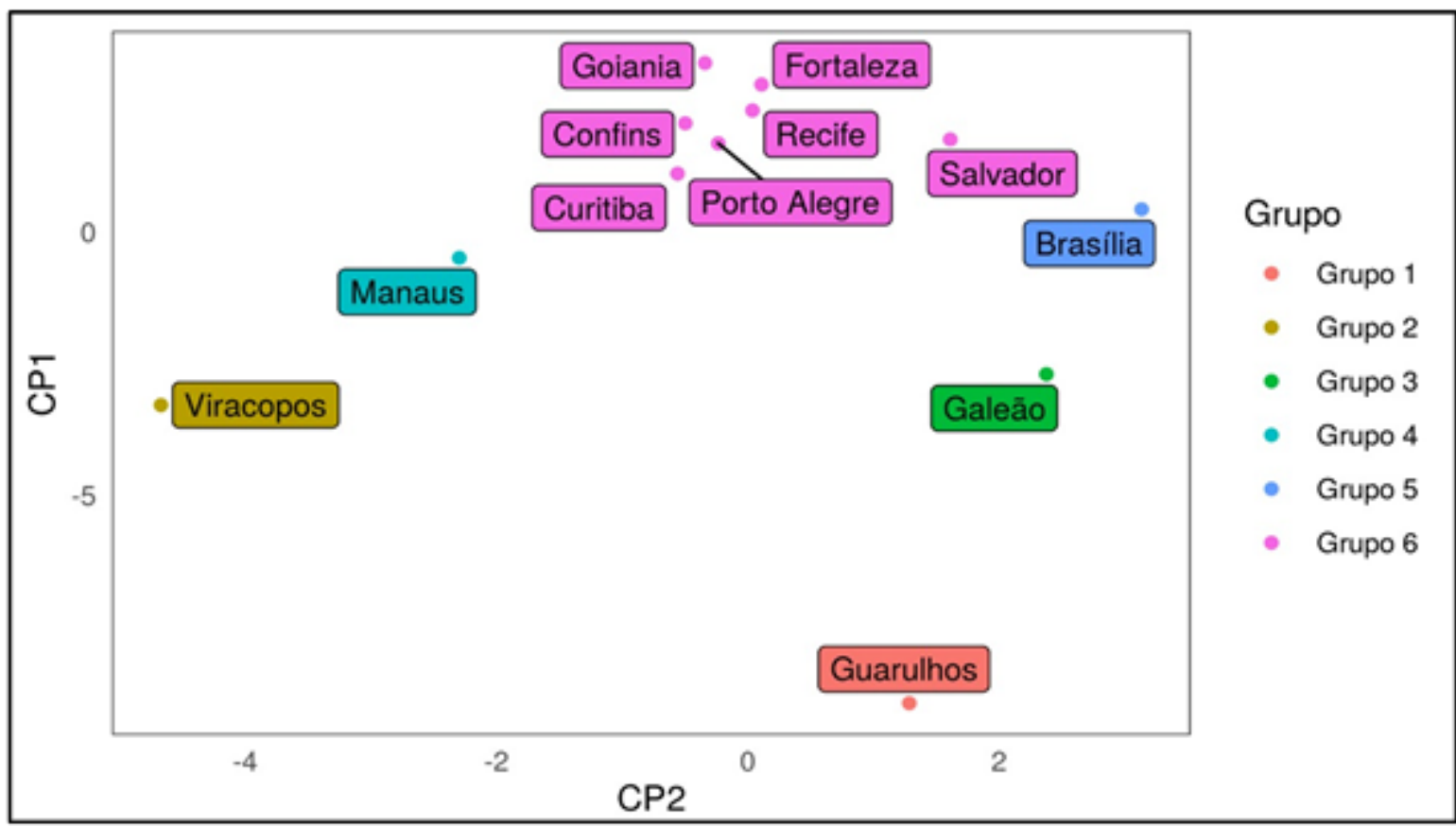

Fonte. Dados da pesquisa

Tabela 8. Dados dos valores dos 3 componentes principais e peso por variável

\begin{tabular}{|c|c|c|c|c|c|c|c|c|}
\hline & \multicolumn{3}{|c|}{ AUTOVETORES } & \multicolumn{3}{|c|}{$\begin{array}{c}\text { VALORES } \\
\text { NORMALIZADOS }\end{array}$} & \multirow[t]{2}{*}{$\begin{array}{l}\text { Peso } \\
\text { médio }\end{array}$} & \multirow[t]{2}{*}{$\begin{array}{l}\text { Input / } \\
\text { Output }\end{array}$} \\
\hline & $\mathrm{PC} 1$ & $\mathrm{PC} 2$ & PC3 & $\mathrm{PC} 1$ & PC2 & PC3 & & \\
\hline Área do pátio aeronaves & $-0,18622$ & 0,18 & $-0,20$ & 72,80 & 66,46 & 14,41 & 51,223 & INPUT \\
\hline Área TECA Doméstico & $-0,20145$ & $-0,27$ & 0,10 & 77,42 & 0,00 & 47,63 & 41,683 & INPUT \\
\hline Área TECA Exportação & $-0,27584$ & $-0,07$ & $-0,09$ & 100,0 & 29,35 & 26,66 & 52,003 & INPUT \\
\hline Área TECA Importação & $-0,24126$ & $-0,22$ & $-0,09$ & 89,50 & 6,66 & 26,48 & 40,879 & INPUT \\
\hline Companhias Aéreas & $-0,26917$ & 0,11 & 0,01 & 97,97 & 55,93 & 37,75 & 63,885 & INPUT \\
\hline Comprimento linear total & $-0,17879$ & 0,32 & $-0,16$ & 70,55 & 87,49 & 19,34 & 59,128 & INPUT \\
\hline Conexões empresariais & $-0,24938$ & 0,17 & 0,00 & 91,97 & 64,33 & 36,67 & 64,323 & $\overline{\text { INPUT }}$ \\
\hline Faturamento TECA & $-0,25593$ & $-0,20$ & $-0,08$ & 93,96 & 9,62 & 27,94 & 43,838 & OUTPUT \\
\hline Fluxo origem-destino & $-0,22100$ & 0,16 & 0,33 & 83,36 & 63,19 & 74,28 & 73,608 & OUTPUT \\
\hline Ligações aéreas & $-0,12570$ & 0,41 & 0,04 & 54,44 & 100,0 & 41,25 & 65,230 & INPUT \\
\hline Mov. Anual de cargueiros & $-0,25344$ & $-0,08$ & 0,08 & 93,20 & 27,46 & 46,23 & 55,633 & INPUT \\
\hline Mov. Anual pouso & $-0,20744$ & 0,28 & 0,07 & 79,24 & 81,31 & 45,26 & 68,603 & INPUT \\
\hline $\mathrm{N}^{\circ}$ posições pátio & $-0,23635$ & 0,23 & 0,05 & 88,01 & 73,74 & 42,70 & 68,153 & INPUT \\
\hline PIB da rede de influência & $-0,23572$ & 0,16 & 0,06 & 87,82 & 63,57 & 44,20 & 65,200 & INPUT \\
\hline PIB per capita da rede & $-0,20549$ & $-0,05$ & $-0,19$ & 78,65 & 31,65 & 15,79 & 42,028 & INPUT \\
\hline Processamento Carga & $-0,05222$ & \begin{tabular}{|c|}
$-0,11$ \\
\end{tabular} & 0,56 & 32,14 & 23,55 & 100,0 & 51,896 & OUTPUT \\
\hline Produtividade TECA & $-0,11189$ & $-0,18$ & $-0,33$ & 50,25 & 12,62 & 0,00 & 20,955 & OUTPUT \\
\hline Resultado & $-0,25087$ & $-0,20$ & $-0,13$ & 92,42 & 9,29 & 22,00 & 41,237 & OUTPUT \\
\hline Tempo desembaraço & 0,05368 & 0,362 & 0,173 & 0,00 & 93,07 & 17,67 & 36,913 & OUTPUT \\
\hline Vol. Anual carga & $-0,15406$ & $-0,06$ & 0,50 & 63,04 & 30,37 & 92,44 & 61,950 & OUTPUT \\
\hline Vol. Anual carga & $-0,26509$ & $-0,11$ & $-0,07$ & 96,74 & 23,81 & 28,73 & 49,757 & OUTPUT \\
\hline Vol. Anual carga & $-0,24024$ & $-0,25$ & $-0,05$ & 89,19 & 2,88 & 31,24 & 41,102 & OUTPUT \\
\hline
\end{tabular}

Fonte. Elaborado pelos autores 
O grau de competitividade foi calculado a partir do conceito de eficiência, obtido pela produtividade agregada já mencionada anteriormente, cujos resultados apontam Viracopos como terminal de carga mais competitivo, ou seja, com a maior eficiência logística, seguido por Manaus, Guarulhos, Curitiba, Galeão, Confins, Porto Alegre, Goiânia, Recife, Fortaleza, Salvador e Brasilia, conforme descrito na Tabela 9.

Tabela 9. Produtividade agregada e índice de eficiência dos aeroportos selecionados

\begin{tabular}{|l|c|c|}
\hline AEROPORTO & $\begin{array}{c}\text { PRODUTIVIDADE } \\
\text { AGREGADA }\end{array}$ & $\begin{array}{c}\text { İNDICE DE } \\
\text { EFICIÊNCIA }\end{array}$ \\
\hline Viracopos & 698,67 & 1,0000 \\
\hline Manaus & 337,97 & 0,4837 \\
\hline Guarulhos & 221,89 & 0,3176 \\
\hline Curitiba & 128,67 & 0,1842 \\
\hline Galeão & 100,92 & 0,1444 \\
\hline Confins & 69,37 & 0,0993 \\
\hline Porto Alegre & 47,20 & 0,0676 \\
\hline Goiania & 36,79 & 0,0527 \\
\hline Recife & 27,36 & 0,0392 \\
\hline Fortaleza & 20,47 & 0,0293 \\
\hline Salvador & 14,44 & 0,0207 \\
\hline Brasilia & 14,31 & 0,0205 \\
\hline
\end{tabular}

Fonte. Elaborado pelos autores

Para o cálculo da eficiência foram excluídos os inputs exógenos e subjetivos, tais como conexões empresariais, PIB da rede e PIB percapita, devido à relatividade em relação ao movimento de carga. Foram excluídos os outputs faturamento e resultado, tendo em vista não serem consideradas no estudo as cargas isenta de tarifação e em perdimento, pois traria resultados inconsistentes.

\section{Considerações Finais}

O estudo investigou quais são as variáveis determinantes para mensuração da competitividade ou atratividade de carga aérea pelos aeroportos em seus terminais de carga próprios, descrevendo sucintamente o mercado de carga aérea aeroportuária nacional, características do setor e apresentando dados sobre os aeroportos líderes em movimentação de carga.

A partir dos dados expostos sobre a movimentação de carga e aeroportos, podese inferir que há uma forte concentração de fluxo de carga nas regiões de maior desenvolvimento industrial, comercial e de serviços no Brasil, e que apresentam um maior fluxo de passageiros. Estes aeroportos receberam um maior aporte de investimentos ao longo dos anos e concentraram, também, um maior fluxo de passageiros, sendo que este fluxo induz a uma maior movimentação de carga doméstica.

$\mathrm{O}$ aeroporto de Guarulhos apresenta maiores quantitativos na maioria das variáveis, com exceção de Viracopos nas variáveis em área Teca importação, faturamento, PIB per capita da rede, resultado, volume anual importação (ton.) e tempo de desembaraço aduaneiro. Galeão lidera em comprimento linear total de pistas. Brasilia lidera em ligações aéreas domésticas e produtividade não agregada e Manaus em volume anual de carga doméstica (ton.) e processamento de carga (ton./área). 
A infraestrutura aeroportuária é de fundamental relevância, pois reflete na capacidade operacional do aeroporto e no processamento de cargas nos armazéns, o que impacta diretamente a demanda, pois esta é dependente da disponibilidade das instalações aeroportuárias. Por conseguinte, um aeroporto mesmo possuído ótima localização, será ineficaz se não houver uma infraestrutura suficiente para absorver a demanda. O desenvolvimento dos mercados nos quais os aeroportos estão inseridos são fatores determinantes para a competitividade do setor aéreo de cargas, pois a presença de complexos industriais, zonas econômicas, comerciais e de livre comércio, alta densidade demográfica, acompanhada por elevado PIB per capita, influenciam na movimentação de passageiros e cargas nos aeroportos.

Pelos resultados apresentados na Tabela 8, no grupo operação as variáveis ocupam as maiores relevâncias para competitividade, com destaque para movimento anual pouso-decolagem, na segunda posição, quantidade de ligações (conexões) áreas domésticas na quarta posição, quantidade de companhias aéreas operando na sétima posição e movimento anual de cargueiros na décima posição.

No grupo infraestrutura destaca-se na terceira posição de relevância a quantidade de posições no pátio de aeronaves e comprimento linear total de pistas na nona posição. $\mathrm{Na}$ variável localização o PIB da rede de influência ocupa a quinta posição e conexões empresariais a sexta posição. No grupo demanda, o fluxo total carga origem-destino doméstico em toneladas ocupa a primeira posição de relevância entre as variáveis, mas com a variável volume anual TECA carga doméstica ocupando a oitava posição.

A partir do método proposto, e corroborando com avaliação de eficiência logística de instituições como a International Air Transport Association (IATA), Viracopos é o aeroporto mais eficiente e competitivo no Brasil.

\section{Limitações de Pesquisa e Proposta de Futuros Estudos}

Os estudos sobre transporte aéreo concentram-se no transporte de passageiros e transportadores aéreos. São poucos estudos relacionados ao transporte de carga aérea no Brasil, tendo em vista a escassez de dados sobre o setor. Informações detalhadas sobre os aeroportos e movimentação de carga são restritas ao público externo, dificultando a elaboração de estudos acadêmicos.

Com as concessões aeroportuárias ficaram ainda mais restritas as informações. Ao se realizar um estudo comparativo entre variáveis é necessário que as informações sejam de um mesmo ano, o que limitou o trabalho ao recorte do ano de 2010. Como sugestão para futuros estudos pode-se utilizar os dados expostos neste artigo adicionados à pesquisa com especialistas do setor de forma a adotar outras técnicas de análise como o método Delphi, por exemplo. Também pode ser realizada pesquisa de roteamento de frota de transportadores cargueiros de forma a identificar a importância de transportadoras dedicadas no setor, ou mesmo modelos multi-decisão, avaliando cada fator componente de um grupo de fatores centrais usando o método de pontuação e avaliação agregada de cada grupo fator-chave e valores ponderados para cada grupo de fator principal. Outras técnicas podem ser utilizadas para se averiguar a eficiência produtiva como Análise Envoltória de Dados (DEA), entre outras.

\section{Referências}

AIRBUS S.A.S. Global Market Forecast - Future Journeys 2013-2032. USA, 2013. 
ANAC (Brasil). Anuário Estatístico do transporte aéreo 2010. Brasîlia, 2010.

\section{1 .} . Relatório do Desempenho Operacional dos Aeroportos Ano base 2011, Brasília, Anuário Estatístico do transporte aéreo 2017. Brasília, 2017.

BLUNCK, S. Modellierung und Optimierung von Hub-und-Spoke-Netzen mit beschränkter Sortierkapazität, Karlsruhe 2005.

BOUDOIN, D. Logística-Território-Desenvolvimento: O caso europeu. I Seminário Internacional: Logística, Transporte e Desenvolvimento. Ceará: UFC/CT/DET p 105, 1996.

BNDES. Estudo do Setor de Transporte Aéreo no Brasil. Rio de Janeiro. 2010.

CHAO, CHING-CHENG; YU, PO-CHENG. Quantitative evaluation model of air cargo competitiveness and comparative analysis of major Asia-Pacific airports. Transport Policy 30, 318-326, 2013.

DOGANIS, R. Flying off course - The Economics of International Airlines. Editora N. York Press, 1985.

GARDINER, J; ISON, S; HUMPHREYS, I. Factors influencing cargo airlines' choice of airport: An international survey. Journal of Air Transport Management 11. 393-399. 2005.

GRUENSCHLOSS, C. The development of international airports into air cargo hubs and its economic impact on local industrial structures. Heinrich-Heine University Düsseldorf. 2005.

INFRAERO (Brasil). Relatório de Movimento Operacional - Logística de Carga, 2010.

INFRAERO (Brasil). Relatório Anual 2010.

INFRAERO (Brasil). Relatório Opnet 2010.

LARRODÉ, E.; MUERZA, V.; VILLAGRASA, V. Analysis model to quantify potential factors in the growth of air cargo logistics in airports. XIII Conference on Transport Engineering, CIT2018 Transportation Research Procedia 33, 339-346. 2018.

LEE, H. Air cargo hub competition in Northeast Asia. Airport systems Planning, Design, and Management December 6th, 2007.

MCKINNON, A. The air cargo industry and transhipment in Hongkong: Challenges, opportunities and global competitiveness. Working Paper Series City University of Hong Kong. August 2011.

OKTAL, H.; OZGER, A. Hub location in air cargo transportation: A case study. In: Journal of Air Transport Management. 2013.

NETO, C. M. C. P; CASAGRANDE, P. L.; LANCIERI, F. M.; MORAES, J. N. P. Procompetition rules in airport privatization: International experience and the Brazilian case. In Journal of Air Transport Management 4, 9-16, 2016.

RECEITA FEDERAL DO BRAIL (Brasil). Relatório de Desembaraço Aduaneiro: canal verde. Receita Federal do Brasil, 2018. 
SENGUTTUVAN, P. Air cargo: Engine for economic growth and development - A case study of Asian Regions. National Urban Freight Conference - 1-3rd February 2006. University of Southern California, Los Angeles, USA. 2006.

SIT, V. Global TransPark: New Competitiveness for Hong Kong and South China Based on Air Logistics. Geogr, Ann. 86 B (3): 145-163, 2004.

TCU (Brasil). Fiscalização Financeira e Controle da Câmara dos Deputados: auditoria na ECT. TC 014.882/2010-8. Brasilia, 2010.

WONG, J. T.; CHUNG, Y. S.; HSU. P. Y. Cargo market competition among Asia Pacific's major airports. Journal of Air Transport Management 56, 91-98, 2016.

ZHANG, A. Analysis of na international air-cargo hub: the case of Hong Kong. J. Air Transport Manage. 9(2), 123-138, 2003.

ZONDAG, W. J. Competing for Air Cargo - A qualitative analysis of competitive rivalry in the air cargo industry. Dissertação de Mestrado em "Business Administration". Free University of Amsterdam. Amsterdam, 2006. 